\title{
Housing Standards, Household Health and Disease Nexus in the Buea Municipality
}

\author{
Fombe Lawrence Fon ${ }^{1} \&$ Agbortoko Manyigbe Ayuk-Nkem ${ }^{1}$ \\ ${ }^{1}$ Department of Geography, University of Buea Cameroon, Cameroon \\ Correspondence: Fombe Lawrence Fon, Department of Geography, University of Buea Cameroon, Cameroon. \\ E-mail: ezumeh@hotmail.com
}

Received: October 31, 2013 Accepted: July 3, 2014 Online Published: July 31, 2014

doi:10.5539/jsd.v7n4p262

URL: http://dx.doi.org/10.5539/jsd.v7n4p262

\begin{abstract}
Housing has considerably evolved over time and space in terms of standards but much still needs to be desired since some household diseases are intricately linked to housing standards with profound effects on the health of the occupants. This study seeks to examine the physical characteristics of houses and their standards in relation to health and disease. Data was collected through observations and interviews. Field data reveals that over $70 \%$ of the housing standards have improved over the past two decades. This notwithstanding, there is a positive correlation between standard/substandard housing on the one hand and disease/poor health conditions on the other. This is mostly linked to housing type, structural layout and environmental conditions as observed in parts of the rapidly urbanising settlement of Buea; a university town and regional capital of the Southwest in Cameroon. In order to reduce the proliferation of communicable diseases like typhoid, cholera and malaria, housing upgrading and refurbishments should be matched with local planning objectives if improved health is to be anticipated by the population in this tropical settlement.
\end{abstract}

Keywords: substandard housing, Buea municipality, refurbishments, disease propagation, housing quality standards

\section{Introduction}

The affordability of housing has clear implications on health. This is because the shortage of affordable housing limits families in individual choices about where they live thereby, relegating lower income families to substandard housing in unsafe, overcrowded neighbourhoods with higher rates of poverty and fewer resources for health promotion like in New Bell neighbourhood in Douala (Fombe, 2005). The intimate nexus between housing, its evolution and impact on health is not new. Florence Nightingale (1912) quoted that "the connection between housing and the dwelling of population is one of the most important that exist". It must be noted that there is a clear link between housing evolution, housing standards and the proliferation of various diseases like cholera, malaria, skin diseases among others. The living homes around the marshes of Bonaberi-Douala record the highest incidence of malaria (Ehumka, 2010) due to their substandard nature and appalling environment. In the United Kingdom, evidence in the early 2000s examining the relationship between housing quality and health have largely been developed by two separate traditions of investigation; that of social science and epidemiological and or medical research. But no matter the field that points out the relationship between housing and health, evidence from either fields point to the fact that housing quality affects health. According to the Housing and Urban Development Department (1965), there are 13 performance requirements to encompass housing standards. They include sanitary facilities, food preparation and refuse disposal, space and security, thermal environment, illumination and electricity, structure and material, interior air quality, water supply, lead-based paint, access, site and neighbourhood as well as smoke detectors.

Eze B. (2008) indicates that indoor air pollution among low income communities in Lagos revealed that people living in houses with minimal ventilation reported extremely high incidences of blocked or running noses, (86\%) chronic cough and eye irritation (79\%) as well as shortness of breathe (57\%). According to the National Agency for Housing (SIC) (2006) only $28 \%$ of urban dwellers have standard housing, with a massive $62 \%$ having poor to inadequate housing, whereas $70 \%$ have substandard. To supplement the need for housing, the agency has undertaken several housing schemes nationwide. Housing in Buea has experienced some remarkable changes only in recent times due to increasing demand by university students for standard housing. However, given this 
improvement there is a sluggish drive towards the upgrading of the housing environment. This has affected health conditions of the population. Like in other towns of sub-Saharan Africa, Buea is prone to tropical diseases such as malaria, cholera, and dysentery among others. The quality of housing is supposed to be at least of average standard so as to reduce the proliferation of these tropical diseases.

A closer study of Buea suggests that housing quality determines the rate of diseases people suffer from. Most of the housing environment is characterized by the use of sub-standard corrugated iron sheets and non-durable materials such as wood for the walls. The absence of toilet systems and piped water has further compounded the housing standards. Due to land scarcity in the study area, houses have been constructed haphazardly creating situations where toilets are poorly located or pathways and streets are absent. Little attention has been paid by most environmental health and planning officials to the social and structural conditions underlying housing materials, which may directly affect susceptibility to toxic exposures themselves. This incorporates a range of social and physical determinants of environmental pollution, illustrating how these conditions result in health and illness. In most Third world cities, little attention is accorded to the problem of disease that result from poor housing and environmental conditions probably due to rapid and uncontrolled urbanization. The study seeks to illustrate the importance of the housing environment in determining the state of health of the population with reference to the southern part of Buea.

\section{The Study Matrix and Methodology}

\subsection{The Study Matrix}

Buea is an urban settlement situated at the foot of Mount Fako. It is located between latitude $4^{\circ} 14^{\prime \prime}$ north of the equator and longitude $9^{\circ} 20^{\prime \prime}$ east of the Greenwich Meridian. Figure 1 illustrates the location of Buea in Fako Division on the southern slope of Mt. Cameroon. Besides being the capital of the Southwest Region, Buea is a university and colonial settlement which has grown to attain a current population of over 200,000 from 46,000 in 2000 (Fombe \& Balgah, 2012).



Figure 1. Location of Buea in Fako division, south west region of Cameroon

Source: Adapted from the National Institute of Statistics, 2009.

Generally, parts of Buea are built on the risk zone of Mount Fako. This region is characterized by various physical pressures of hazard phenomena with soils composed principally of volcanic bombs and scoria that render the region rough and stony. Buea is situated along the Cameroon Volcanic Line; some 30km from the Sea (Gulf of Guinea). The rainfall pattern is modified in the Mount Cameroon area by the highland which interrupts 
the movement of air masses causing considerable orographic rainfall. Buea records an annual rainfall of $3500 \mathrm{~mm}$ (IRAD, Ekona, 1993). Temperatures are considerably high with low annual variations. The mean annual temperature is $23^{\circ} \mathrm{C}$ while the monthly temperature reveals a minimum of about $20^{\circ} \mathrm{C}$ in the month of June and July accounted for by heavy rainfall in these months.

\subsection{Methodology}

This study was undertaken in five neighourhoods in southern Buea based on their recent rate of housing transformation and changing landscape resulting from rapid construction of houses. The methodology for the study involved both primary and secondary data. Secondary sources of data collection was invaluable through documents from the municipal archives, published and unpublished materials from resource centers, journals and articles amongst others. Primary data was collected using both the stratified and systematic random sampling techniques. The population of southern Buea was stratified into workers and non-workers with each stratum comprising $10 \%$ of respondents who have lived in the area for over 20 years so as to appreciate the changes on space. Within each stratum, the respondents were randomly interviewed to obtain their views regarding the evolution in building structure, materials and cost of land within the time frame. The opinion of different inhabitants of this zone was also considered as information concerning health problems, the environment they live in as well as the state of housing was needed. Resource persons like the Chief of Molyko, Council officials were also interviewed to obtain information concerning housing evolution, building and construction code, risk prone areas and development perspectives for the area.

A total of 80 questionnaires were distributed to each of the stratum in the five neighbourhoods (Bonduma, Bokoko, Molyko, Bomaka and Bolifamba). Some of these neighbourhoods like Bomaka and Bolifamba have developed on ceded land from the Cameroon Development Corporation (CDC) which has incorporated most of their retired unskilled workers, while Molyko has experienced a very rapid and unprecedented growth in housing due to the creation of the University of Buea in 1993 and the urgent need for housing to accommodate students and staff. The sample size of each stratum was based on the population of each settlement sampled using the 2005 National Population Census results to ensure a representative sample. $79 \%$ of interviewees responded to the questionnaires and the data analyzed was based on this sample size. This was complemented by 10 interviews conducted with the chiefs and notables in the various localities. The Chi-square was used in testing the statement that "the poor physical state of housing in Buea has led to the proliferation of communicable diseases in the southern section".

The study examines the different housing types, and shows how health correlates with housing standards. The health parameters used in the study are malaria, cholera, typhoid and the common cold and are based on the Housing Quality Performance Requirements of the Department of Housing and Urban Development (1965). Six of the parameters (space and security, illumination and electricity, structure and material, water supply, access as well as the site and neighbourhood) are used.

\section{Conceptual View}

For many years, the housing environment has been acknowledged as one of the main settings that affects human health. Living and housing conditions therefore become the basis of many factors influencing residential health. While no commonly agreed upon definition of healthy housing exist, there is consensus on how housing conditions may affect health. Epidemiological findings suggest that there is a strong association between housing conditions and health effects. This study seeks to illustrate that housing environmental conditions in Buea are a key factor influencing the prevalence of diseases such as malaria, cholera, typhoid, and common cold.

There is a lack of fundamental research on housing and health in the context of current urbanization trends which have not been well understood in terms of both the positive and the negative aspects on health and well-being (Fuller-Thomson et al, 2000). Under the overarching theme of the urban environment and health, housing and health has been defined as a priority issue by the WHO (2006). Healthy housing must be a comprehensive concept taking into consideration a variety of factors contributing to the quality of housing and the housing environment. Housing is a complex construct that cannot be represented merely by the physical structure of the home. The WHO understanding of housing is therefore based on a four layer model of housing, taking into consideration the physical structure of the dwelling, the meaning of home (for a family and each individual), the external dimension of the immediate housing environment, as well as the community with all neighbours. For each individual dimension, there is an array of direct or indirect health effects, or as a limitation of the quality of life of the resident as shown in Figure 2 to be home, dwelling, community and immediate environment all having an effect on health and inter-related.

A home perceived as safe and intimate provides major psychosocial benefits. It represents a protected refuge from 
the outside world, enables the development of a sense of identity and attachment - as an individual or as a part of a family, and provides a space to be oneself. Any intention of external factors or stressors strongly limits this feeling of safety, intimacy and control thereby reducing the mental and social function of the home.

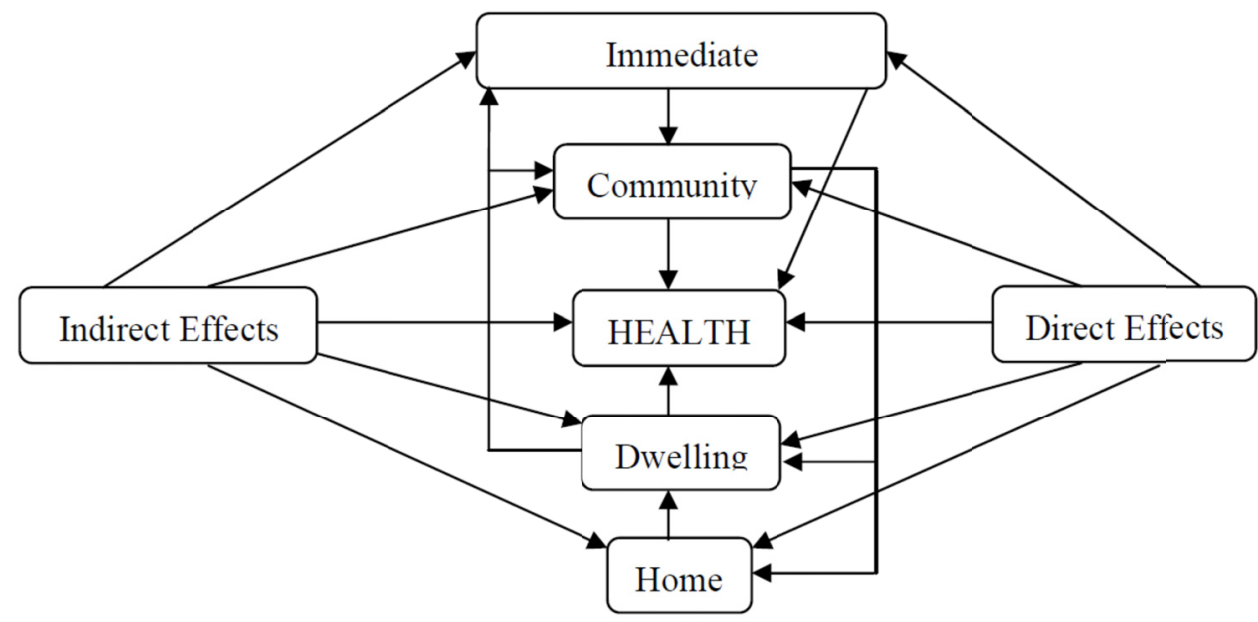

Figure 2. The four dimensions of housing

Source: Adapted from the W.H.O, 2006.

Inadequate dwelling conditions may trigger many of the direct health effects. Mould growth, indoor air pollution, and emissions from building materials are as relevant issues as the occurrence of infestations, or lack of hygiene and sanitation amenities. Crowding and noise are also related to the design and layout of the dwelling. Within the community, a range of health-relevant aspects depend on factors that seem independent of housing conditions. Examples are the health effects with social etiology which strongly depend on education, socioeconomic characteristics, or ethnic compositions of the people building the community within a neighbourhood or a city quarter. Still a large number of studies provide sufficient evidence that the social cohesion of the community and the sense of trust and collective efficacy is to some extent dependent on the quality of a neighbouring hood, which can promote or impede the social interactions through the provision of diverse public places and facilities for social life.

The immediate housing environment has an impact on health through the quality of urban design. Poorly planned residential areas often lacking public services, greenery, parks, playgrounds, and working areas, have been associated with lack of physical exercise, increased prevalence of obesity, cognitive problems in children among others. Symptoms of neighbourhood decline affect residents through both visual mechanisms (litter, pollution, graffiti and many others) and social mechanisms (segregation, increased insecurity).

It is important to realize that each of the four dimensions of housing has the capacity to affect individual health status through physical, mental, or social mechanisms and that the four dimensions are interlinked with each other. In southern Buea especially in areas like Bonduma, Bolifamba and Muea which are dominated by substandard housing, the prevalence of diseases is common given the poor housing/environmental conditions as well as the structural aspects of housing. The creation of the University of Buea in 1993 has seen the emergence of standard housing units to meet up with the increasing student population. But the extent to which such housing conforms to the above prescriptions is a matter of great concern because of the non-respect of construction norms and the absence of other facilities like waste facilities, adequate spacing between houses amongst others.

\section{Results}

\subsection{Housing Types in the Southern Section of Buea}

Only private housing is considered for the classification in this study. The standards are based on the kind of material used for construction (temporary/durable), the environmental conditions of the structure and key housing facilities like piped water and lighting (Drakakis-Smith, 1981). This permitted a classification into three categories (standard, substandard and others) for this study. Based on field data, Table 1 illustrates the great disparities in materials used. Overall, cement block which are durable constitute the dominant type of housing material followed by wooden houses that are generally non-durable and considered to be substandard. Wooden houses constitute $25 \%$ of house types, cement block houses $60 \%$, and mud brick $8.3 \%$. Other forms (mixed 
materials inclusive) constitute $6.7 \%$ of all four settlements. Mud bricks are classified as very poor because of structural stability especially in a zone that is prone to earth tremors (Mt. Cameroon), as well as the high levels of health hazard that such pollutant materials that exposes its occupants to poor health conditions

Table 1. Housing types in lower Buea

\begin{tabular}{lccccc}
\hline \multirow{2}{*}{ Neighbourhood } & \multicolumn{5}{c}{ Type of housing material } \\
\cline { 2 - 6 } & $\begin{array}{c}\text { Wooden } \\
\text { (Substandard) }\end{array}$ & $\begin{array}{c}\text { Cement block } \\
\text { (Standard) }\end{array}$ & $\begin{array}{c}\text { Mud brick } \\
\text { (Very poor) }\end{array}$ & $\begin{array}{c}\text { Others } \\
\text { (Substandard) }\end{array}$ & Total \\
\hline Bomaka & 3 & 8 & 1 & 1 & 13 \\
Molyko & 2 & 13 & 2 & 0 & 17 \\
Bonduma & 4 & 12 & 1 & 1 & 18 \\
Bolifamba & 6 & 3 & 1 & 2 & 12 \\
Total & 15 & 36 & 5 & 4 & 60 \\
Percentage & 25 & 60 & 8.3 & 6.7 & 100 \\
\hline
\end{tabular}

Source: Field data, 2013.

In Figure 3, the housing type combines with the environment and the location to determine its standards as prescribed by the World Health Organisation. These housing types would definitely affect sanitation as well as the proliferation of disease like malaria, cholera, and typhoid.

Private houses are typically made of wooden material and corrugated roofing sheets. The piece of wood used are locally obtained and treated for housing construction. Its availability and low cost in the last quarter of the $20^{\text {th }}$ century explains the widespread dominance of such wooden houses in the area. Presently, the study area is characterized by the increasing use of standard structures made of cement blocks and concrete which is a characteristic of commercial streets with certain planning norms like spacing between houses respected which is not the case within the residential neighbourhoods.



Figure 3. Indigenous housing types in lower Buea (Bolifamba)

The evolution in the housing structures over a period of 30 years is illustrated in Figure 4. Overall, from 1981 to late 1990s the dominant material used was wood and other forms (mixed materials specifically zinc and wood (plank) and in some cases, concrete mixed with wood). However, since 1995 there has been a gradual and steady change verging towards greater use of cement. This radical transformation in Molyko can partly be explained by the presence of the University of Buea and other higher institutions of learning with students soliciting better 
living conditions of housing.



Figure 4. Housing evolution over the past 34 years

Source: Fieldwork, 2012 and data for 1981 to 2010 obtained from Buea Municipal Archives, 2012.

Based on information from the District Health Centre Buea, the main illnesses that are prevalent in the municipality are malaria, typhoid, dysentery and cholera in decreasing order, though malaria cases dropped by 27.6\% between 1995 and 2011. There has been a clear reduction in the four forms of diseases in the study sites which relates with the improvement in the pattern of housing development. Figure 5 shows a general drop in the number of cases of the common diseases between 1995 and 2012 though Bolifamba and Muea still remain high above the average level of 173. Bolifamba and Muea for example, recorded a high number of cases of 255 and 160 respectively in 2012 compared to 133 in Molyko and 142 for Bunduma. The housing standards for Molyko and Bunduma have improved substantially over the past 12 years.

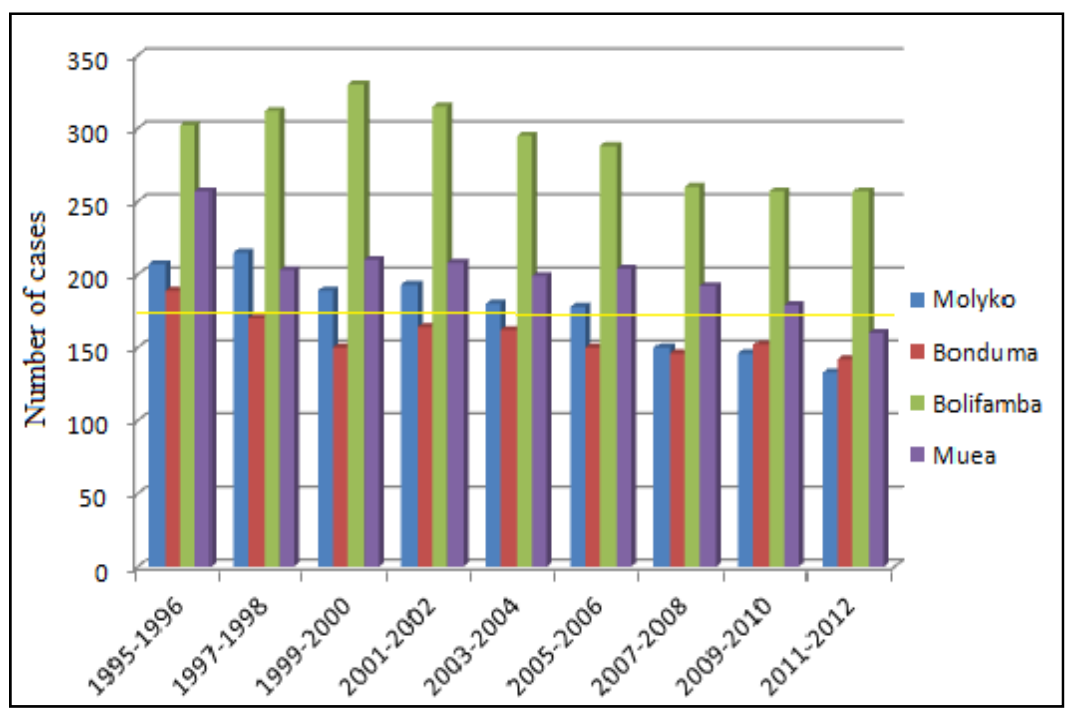

Figure 5. Disease prevalence in lower Buea from 1995 to 2012

Source: District hospital, Buea, 2012.

Malaria shows the highest disease rate within substandard housing structures (Table 2). The prevalence can also be attributed to the environmental conditions and poor physical state of the structures principally in Bolifamba and Muea. As far as the four settlements are concerned, respondents alluded to the fact that there are four main 
diseases. These include malaria, cholera, typhoid and common cold (Catarrh, cough among others). Though, the diseases vary with locality, it is nonetheless evident that they are the most dominant health concerns identified by the local residents.

In order for housing to be seen as standard, it must be durable and structurally stable, have adequate lighting, heating and ventilation, physical accessibility, possess suitable environmental quality and health related factors and have adequate security. Without the above qualifications, it is seen as inadequate, substandard or very poor housing. Based on the data obtained from 4 locations in lower Buea (Bonduma, Molyko, Bomaka and Bolifamba), standard housing constitute over $60 \%$, substandard housing $25 \%$ while very poor housing represents $15 \%$. On the other hand, four main diseases were noticed to be prevalent in all 4 locations and these diseases include malaria, typhoid, cholera and common cold. But as far as these diseases are concerned, malaria and common colds are generally more prevalent $(51.7 \%$ and $25 \%$ respectively), while cholera $(5.0 \%)$ and typhoid $(18.3 \%)$ are rare but found in lower Bolifamba. The disease prevalence according to the three categories of housing is illustrated in Table 2 .

Table 2. Disease prevalence based on housing type in selected neighbourhoods of Buea

\begin{tabular}{lcccc}
\hline Disease & \multicolumn{3}{c}{ Prevalence by housing type (\%) } & $\begin{array}{c}\% \\
\text { of total }\end{array}$ \\
\cline { 2 - 4 } Malaria & Standard & Substandard & Very poor & 51.7 \\
Cholera & 40 & 45.4 & 58.8 & 5.0 \\
Typhoid & 0.0 & 0.0 & 5.9 & 18.3 \\
Common Cold & 20 & 18.2 & 17.7 & 25.0 \\
Total & 40 & 36.4 & 17.6 & 100 \\
\hline
\end{tabular}

Source: Fieldwork, 2013.

Malaria is a generally rampant disease although respondents in some locations raised concerns about the prevalence of other diseases like typhoid. In lower Bolifamba, typhoid and cholera outbreaks are often reported such as the outbreak in July 2012 in Bolifamba, Bomaka and parts of Muea (Regional Hospital, Buea 2013). Sanitary Officials indicated that housing morphology, encroachment of inhabitants onto river valleys and poor waste disposal attitudes are generally neglected in most of the neighbourhoods under study. Cholera outbreaks as well as typhoid are more common in Bolifamba. These are areas with streams that are used as wash points for vehicles that easily contaminate the water source used by some residents. Generally, the rate of disease prevalence (malaria and common cold) tends to be dominant in the very poor and substandard housing neighbourhoods like Bolifamba.

As observed, there is a correlation between housing and health with a high degree of disease occurrence in cases of inadequate and poor housing. This relationship was tested statistically using the chi-square $\left(\mathrm{X}^{2}\right)$ test based on the data collected on housing standards and its impact on health. Using the formula for the chi-square test the results for the expected and the observed frequency for each category was obtained, indicating a table value of chi square with degree of freedom 9 at $0.05 \%$ level of significance as 16.92 . Since the table value with degree of freedom 9 at $0.05 \%$ level of significance (16.92) is greater than the calculated value (1.97), it was obvious to conclude that poor housing development in Buea is not a direct cause of the proliferation of communicable diseases in the study sites. Other causes like the environment, water problems, poor education, hygiene and sanitation have been known to substantially contribute to poor health conditions.

\subsection{Housing, Environment and Health}

Generally marshy and poorly drained environments affect the health and wellbeing of the residents in the southern section of Buea. Malaria is highly prevalent within zones of low environmental quality like Bolifamba and Muea. Some areas like Ndongo in Molyko with standard structures were also noted to exhibit a high rate of malaria mainly due to indiscriminate waste disposal, marshy environments and the availability of stagnant pools of water that propagate mosquitoes. Furthermore, the high rate of population influx and high land values (Note 1) has forced some people to occupy flood prone environments as shown in Figure 6. Such environments especially within Malingo Street are noted to be susceptible to floods during the rainy season and marshy in the dry season. This condition creates a breeding ground for mosquitoes and related infectious parasites (Holy Child Health 
Foundation, 2013).

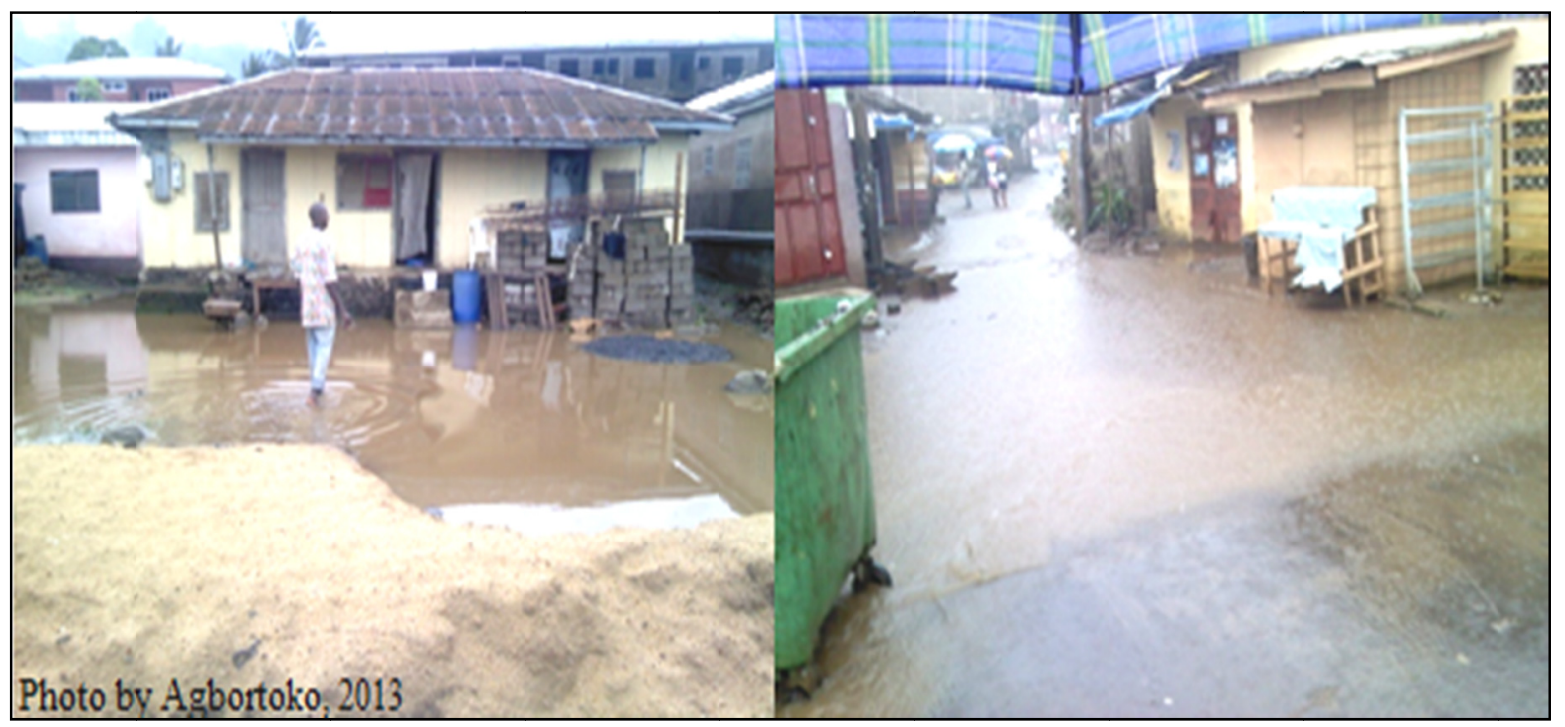

Figure 6. Flood zones within Malingo Street in Buea in August 2013

\section{Discussion}

Housing type has experienced radical changes proportionate to the activity and location of the neighbourhood. Presently, the southern part of Buea is attracting a lot of population and commercial activity and the demand for improved housing by the growing student population of the University of Buea and other institutions of learning is a major springboard for the upsurge of standard housing.

In the background of improved housing, disease prevalence is expected to drop. Unfortunately, this is not the situation in the study area because the location of some standard housing renders them vulnerable and unattractive in terms of the environment such as steep slope and poor accessibility. This explains why in some neighbourhoods like Malingo, Molyko and Mile 16, the prevalence of diseases like common colds, typhoid and malaria is still evident though Milkinson (1989) points out that poor housing in most cases tend to mean disease proliferation especially tropical communicable diseases with different intensities as the housing quality varies. However, he concludes that housing does not simply operate as insulation to influence health; rather they interplay between structural forces, the broader policy environment, and employment opportunities, educational achievements, neighbourhood conditions, social relationships and housing conditions. This means that a standard house in terms of durable materials is not a good measure of its appropriateness for human living. Standards must comply in all what it takes to ensure health, environment and community safety (waste management consciousness) which is lacking in most of the neighbourhoods in the study area.

It can be drawn from the correlation analysis that housing quality is linked to health though at different intensities. This is equally asserted by a 2005 study by Habitat for Humanity which establishes a relationship between poverty, inadequate housing and poor health. It is not in all cases that improvement in housing can imply better and improved living and health conditions. It will take other externalities and internal housing conditions like social characteristics (culture), income level/methods of waste disposal, pollution (Eze, B., 2008), and room density respectively to ascertain a positive correlation rather than subscribe basically to communicable diseases as opined by Pacione (2009) in his analysis of rental housing types in developing countries. The financial burden of affordable housing can prevent families from meeting other basic needs including nutrition and health care, and is particularly significant for low income families. Bunduma and Molyko for example are neighbourhoods that are gradually embracing not only improved housing conditions but middle-income residents which partly explain its low prevalence level of the common diseases.

\section{Conclusion}

This study has examined the physical characteristics of houses and their standards in relation to health and disease. Standard housing is not just the use of contemporary and durable housing material to ensure health and safety of its occupants. It involves a much more holistic approach to the problems of health, hazards and the well 
being of those who seek shelter in it. For many in the southern section of Buea, this seems an elusive concept. The population should be aware that housing must therefore be a comprehensive concept taking into consideration a variety of internal and external factors contributing to its quality. Even though the evolution in housing standards has taken a decisive turn, the outcome leaves much to be desired in this rapidly expanding regional capital of the Southwest. Consequently, the health and standards of the population need to be upgraded as part of its sustainable development drive aimed at meeting the challenges of the Millennium Development Goals. A healthy home is not a specially designed house; it is also a residential setting that is capable of fulfilling the expectations of the residents (WHO, 2006). To achieve this goal implies the collective efforts of both the resident population and the local planning authorities who must address the problems linked to housing and environmental standards.

\section{Recommendations}

In order to reduce the proliferation of communicable diseases like typhoid, cholera and malaria, housing upgrading and refurbishments should be matched with local planning objectives if better health by the population is to be anticipated. This responsibility is to be borne by the population and housing developers. The need to adhere to the use of conventional building materials such as cement for walls is inevitable especially given the unstable nature of the environment that is prone to volcanic and earthquake tremors.

Building and construction regulations have to be strictly enforced to ensure that the population does not encroach unto wetlands and river valleys where they build substandard housing and are eventually exposed to very poor environmental/health conditions. The local planning authority is more concerned with raising income than ensuring the health of the population through the granting of building permits in 'unauthorised' sites or poorly erected structures and later become complacent in addressing the issues when health related problems arise. The enforcement of standards and building norms imply the use of durable materials, supply of vital housing facilities like electricity, ensure proper ventilation and environmental housing quality.

From a holistic perspective, housing characteristics and standards can be ensured by adequate surveys, planning and provision of basic services like water, electricity, drainage, streets, and waste clearance facilities by the planning institution.

\section{References}

Belfer Centre for Science and International Affairs. (2009). Housing and Health. Harvard University, Havard.

Bonnefoy, X. (2007). Inadequate Housing and Health: An Overview, International Journal of Environment and Pollution, 30(3-4), 411-429. http://dx.doi.org/10.1504/IJEP.2007.014819

Buh, A. A. (2006). Changing Housing Patterns and Impact on Health in Cameroon, Unpublished M.A Thesis, University of Yaounde I.

Department of Housing and Urban Development. (1965). A Publication of the United States Cabinet.

Drakakis-Smith. (1981). Urbanisation, Housing and the Development Process. Croom Helm, London.

Ehumka, E. (2011). Human vulnerability to floods and socio-economic implications: Case study of Limbe municipality, dissertation, University of Bamenda.

Eze Bassey, E. (2008). Procedures for assessing, transforming and evaluating housing. University of Calabar.

Fombe, L. F. (2005). Substandard Housing and Slum Development in the Douala Metropolis: An Urban Development Perspective, $\mathrm{PhD}$ thesis (Unpublished), Buea, University of Buea.

Fombe, L. F., \& Balgah, S. N. (2012). The Urbanisation Process in Cameroon, Patterns, Implications and Prospects. Nova, New York.

Fuller-Thomson, E., Hulchanski, J. D., \& Hwang, S. (2000). The Housing/health Relationship: What do we know? Reviews on Environmental Health, 15(1-2), 109-133. Retrieved May 18, 2013, from http://www.unhabitat.org

IRAD. (1998). Annual Report. Institute for Agronomic Research, Ekona.

Milkinson, R., \& Gary, A. (1989). An Overview of Changing Housing Pattern, Structural Stability and Durability. Holt, Rinehard and Winston of Canada Ltd., Toronto, Canada.

National Agency for Housing (SIC). (2006). Yaounde, Cameroun.

National Health Service, UK. (2002, April). Housing and Health. UK National Institute for Health and Clinical Excellence.

National Institute of Statistics. (2009). Ministry of Finance and Economy, Yaounde. 
Pacione, M. (2009). Urban Geography: A Global Perspective (3rd ed.). Routledge, London.

Relph. (1976). Place and Placelessness. University of Toronto, Toronto.

UN-Habitat. (2008). The State of African Cities. A framework for addressing urban challenges in Africa. Nairobi, United Nations Human Settlements Programme, 206.

WHO. (2004). Eradicating Preventable Diseases in Sub-Saharan Africa: Reviews, Prospects and Approaches. $2^{\text {nd }}$ International Housing and Health Symposium, Vilnius, Lithuania.

WHO. (2006). Working together for health. Retrieved March 13, 2013, from http://www.who.int/6EF437B9-569E-774522E48D72/whr/2006/whr06_en.pdf

World Bank. (2003). Housing in Africa. Report No. 18963-AF, WB Publication, September $12^{\text {th }} 2003$.

\section{Notes}

Note 1. A piece of land measuring $900 \mathrm{~m}^{2}$ can cost between 8,000 and 10,000 USD (2013 market value).

\section{Copyrights}

Copyright for this article is retained by the author(s), with first publication rights granted to the journal.

This is an open-access article distributed under the terms and conditions of the Creative Commons Attribution license (http://creativecommons.org/licenses/by/3.0/). 